\title{
Yaşamsal Altyapı Sistemlerinin Sıklaştırma Gps A ğlarıyla İzlenmesi Ve Deformasyon Sonuçlarının Yorumlanması: Kocaeli İzdogap Gps Ă̆ı Uygulaması
}

\author{
Haluk KONAK $^{1 *}$, Pakize KÜREÇ NEHBİT ${ }^{1}$, Cankut İNCE ${ }^{1}$ \\ ${ }^{1}$ Kocaeli Üniversitesi, Mühendislik Fakültesi, Harita Mühendisliği Bölümü, Mersin \\ (hkonak/pakize.kurec/cankutince@kocaeli.edu.tr)
}

\begin{abstract}
Öz
Yerkabuğu hareketleri doğal gaz, ulaşım, iletişim enerji vb yasamsal alt yapı sistemlerini olumsuz yönde etkilerler. Bu nedenle ekonomik değeri yüksek olan, kamu hizmetleri kapsamındaki yaşamsal altyapı sistemleri jeodezik kontrol noktaları/ağları yardımıyla düzenli aralıklarla izlenmeleri gerekli ve zorunludur.

$\mathrm{Bu}$ çalışmada, bilimsel amaçlı bir araştırma projesi kapsamında izlenmekte olan Kocaeli İZDOGAP Sıklaştırma GPS Ağı, gerçek bir yaşamsal altyapı izleme sistemi olarak seçilmiştir. Belli aralıklarla izlenmekte olan IZZDOGAP GPS A ğı'ndan elde edilen konum ve hız bilgileri kullanılarak; bölgede olası yıllık yer kabuğu hareketlerini algılayabilme düzeyi ve bu ağı temsil eden bölgesel gerinim parametreleri irdelenmektedir. Elde edilen deneysel bulgular matematik/istatistik modellerle yorumlanmakta, sonuçlar karşılaştırmalı olarak sergilenmektedir.
\end{abstract}

Anahtar Kelimeler: Algılayabilirlik, Hız Alanı, Gerinim, Jeodezik Ağlar.

\section{Monitoring of Lifeline Systems with Densification GPS Networks and Interpretation of deformations: Application of Kocaeli IZDOGAP GPS Network}

\begin{abstract}
Earth crustal movements affect negatively Lifeline systems such as natural gas, electrical power, communication and transportation facilities. Therefore Lifeline systems with high economic value must be monitored temporal with geodetic networks.

In this study, the Kocaeli IZDOGAP Densification GPS Network monitored within the scope of a scientific research project is selected as a real lifeline monitoring system. The sensitivity level of possible annual crustal movements in the region and regional strain parameters of the network are analysed by using position and velocity values of IZDOGAP GPS Network. The experimental findings obtained are interpreted with mathematical / statistical models and the results are presented comparatively.
\end{abstract}

Keywords: Detectability, Speed Field, Strain, Geodetic Networks. 


\section{GİRIŞ}

Kamu hizmetleri kapsamındaki temel sağlık, enerji, ulaştırma ve iletişim ağları yaşamsal sistemler olarak adlandırılmaktadır (KONAK ve EKINCİ, 2005). Bu sistemler, olası doğal afetlerden ve zemine bağlı yerel etkilerden etkilenebilmektedir. Zamanla yıkıcı sonuçlar doğurabilecek bu etklilerin sonuçları hemen farkedilemeyebilir. Bu nedenle bu sistemlerin jeodezik kontrol noktaları/ağları yardımıyla düzenli aralıklarla izlenmeleri gerekli ve zorunludur.

Yaşamsal altyap1 sistemleri için tesis edilen gerek ülke temel ağları, gerekse GPS sıklaştırma ağlarından, ölçme anında kendilerinden beklenen duyarlık ve güvenirlik isteklerini karşılamaları, bunun yanı sıra ağ noktalarından beklenen yıllık yer kabuğu hareketlerini de yeterince algilayabilmeleri beklenmektedir. Bu biçimiyle ülke ağlarının da birer deformasyon ağ 1 gibi izlenmesi gerekli ve zorunlu duruma gelmektedir. Deformasyon ağlarının yeterliliği için datumdan bağımsız birer kalite ölçütleri olan Algılayabilirlik ve Sağlamlık Ölçütleri giderek önem kazanmaktadır.

$\mathrm{Bu}$ çalışmada, bilimsel amaçlı bir araştırma projesi kapsamında izlenmekte olan Kocaeli İZDOGAP GPS Ağı, gerçek bir yaşamsal alt yapı izleme sistemi olarak seçilmiştir. 106 Jeodezik kontrol noktasından oluşan IZDOGAP GPS A ̆ğ1, Kocaeli yerleşim alanında tesis edilen Doğal Gaz Alt Yap1 tesislerinin izlenmesi amaciyla tesis edilmesine karşın, aynı zamanda da KAF kuşağının İzmit-Sapanca bölümünü de kapsamaktadır. Bu biçimiyle IZZDOGAP GPS Ağı, TUTGA hız alanını yer kabuğu hareketlerine bağlı olarak bölgesel anlamda güncelleyebilecek bir işlev kazanmaktadır.

$\mathrm{Bu}$ çalışma iki ana bölümde ele alınmaktadır. Birinci bölümde, belli aralıklarla izlenmekte olan IZDOGAP GPS Ağı'ndan elde edilen hız ve konum bilgileri kullanılarak; bölgedeki olası yıllık yer kabuğu hareketleri ile bu hareketleri algilayabilme düzeyleri belirlenmektedir. İkinci bölümde ise yer kabuğu hareketleri iki boyutlu bir gerinim modeli ile değerlendirlmekte ve elde edilen deneysel bulgular doğrusal hipotez testleri ile sınanmakta, ulaşılan sonuçlar karşılaştırmalı olarak sergilenmektedir.

Araştırmanın Amacı;íkinci düzey başlıklar numaralandırma yapmadan sola dayal1, 11 punto, ilk harfleri büyük, kalın ve italik olarak yazılmalıdır. Kendinden önceki paragraftan bir satır boşluk ile ayrılmalıdır. Biçimlendirmeyi bozmadan bu kısmı silip makale metnini yazabilirsiniz.

\section{JEODEZIK AĞLARDA ALGILAYABÍLİRLÍK}

Jeodezik Ağlarda, her bir epok (ölçme anı) için gerçekleştirilen gözlemler Gauss-Markoff modelinde, En Küçük Kareler İlkesine göre Dolaylı Ölçüler olarak değerlendirilir ve bilinmeyenlerin en uygun değerleri;

$\hat{x}=\left(A^{T} P A\right)^{-1} A^{T} P l$

olarak elde edilir. $t_{1}$ ve $t_{2}$ epoklarında değerlendirilen bir jeodezik ağın dengeli koordinatları arasında;

$d=\hat{x}_{2}-\hat{x}_{1}$

biçiminde bir yer değiştirme vektörü oluşturulur. Ters ağırlıkların yayılması ilkesine göre Deformasyon modelinin ters ağırlıklar matrisi;

$Q_{d d}=Q_{x_{1} x_{1}}+Q_{x_{2} x_{2}}$

elde edilir. İki ölçme anı arasındaki hız vektörü

$\dot{x}=\frac{\hat{x}_{2}-\hat{x}_{1}}{\Delta t}$

olarak yazılırsa, hız vektörünün ters ağırlık matrisi de

$$
Q_{\dot{x} \dot{x}}=\frac{Q_{x_{1} x_{1}}+Q_{x_{2} x_{2}}}{\Delta t^{2}}
$$

eşitliği ile elde edilebilir. Univaryat düzenli jeodezik ağlarda gözlemlerin ağırlıkları, ağın ölçme planı, noktaların dağılımları aynı 
olduğundan, her iki epoktaki ters ağırlıkları da değişmez kalır. $\mathrm{Bu}$ durumda hız vektörünün ters ağırlık matrisi de

$$
Q_{\dot{x} \dot{x}}=\frac{2 Q}{\Delta t^{2}}
$$

şeklini alır.

Deformasyon modelini temsil eden yer değiştirme vektörü ve onun ters ağırlıkları yardımıyla; deformasyon modeline ilişkin test büyüklüğü $\quad\left(T=\frac{d^{T} Q_{d d}^{+} d}{s_{0}^{2} h}\right) \quad$ ve test büyüklüğünün sinır değeri $\left(F_{h, f, 1-\alpha}\right)$ hesaplanır. Ön görülen sınır değerin aşılması durumda ele alınan ağ noktaları arasında anlamlı bir yer değiştirme olduğu kanısına var1lır.

Bir jeodezik ağın, herhangi bir zaman aralığında (peryotta) değerlendirilmesi sonucunda elde edilen kesin değerlerin büyüklüğü ( $\hat{x}$ ), ölçüler vektöründe ( $l$ ) ortaya çıkan olası hatalara bağlıdır. Farklı zamanlarda değerlendirilen bu ağlarda ağın datumunun, yaklaşık koordinatlarının ve deneysel varyansın öncül değerinin değişmemesi önerilmektedir (AKSOY ve diğ., 1995). A $\breve{g}$ noktaları arasında herhangi bir yer değiştirme yoksa ölçüler vektörünün rasgele dağılımlı ölçülerden oluştuğu varsayılır.

$\mathrm{Bu}$ durumda deformasyon modeli, rasgele dağılımlı diferansiyel ölçülerin $(\delta l)$ bir fonksiyonu olarak;

$d=N^{+} A^{T} P \delta l$

biçiminde yeniden düzenlenir ve yer değiştirme vektörünün ters ağırlıkları da hata yayılma ilkesine göre;

$Q_{d d}=N^{+}$

olarak elde edilir. Yer değiştirme vektörü (d), ortalaması $(\bar{d})$, varyansı $\left(\Sigma_{d}\right)$ ve serbestlik derecesi (u) ile normal dağılımda olmak üzere, $\xi_{0}^{2}=\bar{d}^{T} \Sigma_{d d}^{+} \bar{d}$ büyüklüğü Chi-Kare dağılımındadır. Chi-Kare Dağılımı,
$\xi^{2}=\bar{d}^{T} \Sigma_{d d}^{+} \bar{d}=\frac{d^{T} P_{d d} d}{\sigma^{2}} \approx \chi_{u, \xi_{0}^{2}}^{2}$

$\sigma^{2}$, birim ölçünün ortalama hatasının öncül varyansı olmak üzere, sifır hipotezine uyar. Hipotezin geçerli olduğu durumlarda Diş Merkezlik Parametresi,

$\frac{d^{T} P_{d d} d}{\sigma^{2}} \leq \delta_{0}^{2}$

eşitliğini sağlar. (HSU ve HSIAO, 2002). Bu eşitliğin çözümlenmesi sonucunda belirlenebilir en küçük yer değiştirme miktarı elde edilir. (2) eşitliğindeki karesel büyüklük $d^{T} P_{d d} d=d^{T} S \Lambda S^{T} d$, özdeğerler ayırımı ile açık olarak yazılır ve ortogonallik özelliğine göre katkısı olmayan çarpanlardan arındirilırsa,

$d^{T} P_{d d} d=\|d\| \sum_{i=1}^{u} \lambda_{i}$

biçiminde yeniden düzenlenebilir. Deformasyon modelinin diş merkezlik parametresinden $\left(\xi^{2}\right)$ yararlanarak aykırı rasgele hatalar vektörünün büyüklügü;

$\|d\|^{2}=\frac{\delta_{0}^{2} \sigma^{2}}{\sum_{i=1}^{u} \lambda i}$

elde edilir. Bu büyüklük, en büyük özdeğer $\left(\lambda_{\max }\right)$ için yazılırsa, ağın en iyi duyarlık derecesi olarak, belirlenebilir en küçük yer değiştirme değeri yani algılayabilirlik düzeyi;

$\|d\|_{\min }=\frac{\delta_{0} \sigma}{\sqrt{\lambda_{\max }}}$

elde edilir. Buna karşın, bu eşitlik en küçük özdeğer $\left(\lambda_{\text {min }}\right)$ için yazılırsa, ağın en kötü duyarsızlık derecesi anlamına gelen ağın yetersizlik düzeyi;

$\|d\|_{\max }=\frac{\delta_{0} \sigma}{\sqrt{\lambda_{\min }}}$

olarak hesaplanabilir. $\quad\|d\|_{\min }$ ve $\|d\|_{\max }$ değerleri ağın genel ayırma gücü (global sensitivity) hakkinda bilgi verirler. Uygulamalarda ise noktalara göre tanımlanan 
duyarlık ölçütleri oldukça kullanışlıdır. (HSU ve HSIAO, 2002).

(7) numaralı eşitlikte verilmekte olan yer değiştirme vektörü (d), üç boyutlu GPS ağları için;

$\left[\begin{array}{c}d_{x_{1}} \\ \hdashline d_{x_{2}}^{-} \\ \cdot \\ d_{x_{u}}\end{array}\right]=\left[\begin{array}{cccc}N_{11} & N_{12} & \cdot & N_{1 u} \\ \hdashline N_{21} & N_{22} & \cdot & N_{2 u} \\ \cdot & \cdot & \cdot & \cdot \\ N_{u 1} & N_{u 2} & \cdot & N_{u u}\end{array}\right]^{+} \cdot\left[\begin{array}{c}n_{1} \\ n_{2} \\ \cdot \\ n_{u}\end{array}\right]$

biçiminde düzenlenirse, tek bir durak noktası için;

$d_{i}=\left[\begin{array}{llll}N_{11} & N_{12} & \ldots & N_{1 u}\end{array}\right]^{+} \cdot\left[\begin{array}{c}n_{1} \\ n_{2} \\ : \\ n_{u}\end{array}\right]$

olarak elde edilir. Ters ağırlıkların yayılması ilkesine göre

$d_{i}=\left[\begin{array}{l}\delta x_{i} \\ \delta y_{i} \\ \delta z_{i}\end{array}\right]=\ddot{N}_{i} A^{T} P \delta d l$

olmak üzere herhangi bir durak noktasındaki yer değiştirme vektörünün ağırlığı,

$Q_{d_{i} d_{i}}=\ddot{N}_{i} A^{T} P Q_{l l} P A \ddot{N}_{i}^{T}$

$Q_{d_{i} d_{i}}=\ddot{N}_{i} N \ddot{N}_{i}^{T}$

olarak hesaplanır.

Her bir ağ noktası için elde edilen ağırlık matrisinin özdeğerleri irdelenerek algılayabilirlik düzeyleri ayrı ayrı elde edilebilir (KÜREÇ, 2010; KÜREÇ ve KONAK 2014).

Ülke Temel GPS Ağları ya da Sıklaştırma GPS Ağlarındaki bazı noktaların zamanla kaybolması ya da tahrip olması beklenen bir durumdur. $\mathrm{Bu}$ tür ağların belirli aralıklarla izlenmesi durumunda, Multivaryat düzenli ağlar olarak ele alınmaları gerekmektedir. Multivaryat düzenli ağlar için (4) eşitliğindeki hız vektörü ilk ölçülerin bir fonksiyonu yeniden düzenlenir

$\dot{x}=\frac{1}{\Delta t}\left(\ddot{N}_{2} A_{2}^{T} P_{2} l_{2}-\ddot{N}_{1} A_{1}^{T} P_{1} l_{1}\right)$

ve hata yayılma kuralına gore hız vektörünün ters ağırlik matrisi $Q_{\ddot{x} \dot{x}}=\frac{1}{\Delta t^{2}}\left(\ddot{N}_{2} A_{2}^{T} P_{2} Q_{l_{2} l_{2}} P_{2} A_{2} \ddot{N}_{2}^{T}+\ddot{N}_{1} A_{1}^{T} P_{1} Q_{l_{1} l_{1}} P_{1} A_{1} \ddot{N}_{1}^{T}\right)$

$Q_{\dot{x} \dot{x}}=\frac{\ddot{N}_{2} N_{2} \ddot{N}_{2}^{T}+\ddot{N}_{1} N_{1} \ddot{N}_{1}^{T}}{\Delta t^{2}}$

olarak elde edilir.

Tüm epoklarda üst dereceden ağ noktalarının belirlediği datumda ve kısmi iz minimum koşulu altında serbest ağ çözümleri gerçekleştirilirse, bilinmeyenlere ait ters ağırlık matrisleri de her bir epok için ayrı ayrı

$Q_{i}=\left(N+B B^{T}\right)^{-1}-G\left(G^{T} B B^{T} G\right)^{-1} G^{T}$

olarak elde edilir.

$\mathrm{Bu}$ durumda i. durak noktasındaki yer değiştirme vektörüne ilişkin ters ağırlık matrisi, multivaryat düzenli ağlar için

$Q_{d_{i} d_{i}}=\frac{\left(\ddot{N}_{i} N_{1} \ddot{N}_{i}^{T}\right)_{1}+\left(\ddot{N}_{i} N_{2} \ddot{N}_{i}^{T}\right)_{2}}{\Delta t^{2}}$

biçiminde düzenlenir ve ağırlık matrisi de

$N_{i i}=\left\{\frac{\left(\ddot{N}_{i} N_{1} \ddot{N}_{i}^{T}\right)_{1}+\left(\ddot{N}_{i} N_{2} \ddot{N}_{i}^{T}\right)_{2}}{\Delta t^{2}}\right\}^{-1}$

olarak elde edilir.

\section{GERINIM ANALİZi}

Bir ağın güvenirlik düzeyi iç güven ve dış güven ölçütleriyle denetlenmektedir. Uyuşumsuz ölçülerle belirlenemeyen olası hataların küçük olduğu durumlarda sağlam bir ağdan söz edilmektedir. Yalın bir anlatımla; sağlamlık analizleri güvenirlik ölçütlerinin gerinim (strain) teknikleriyle güçlendirilmesi işlemlerinden oluşmaktadır (BERBER, 2006).

Sağlamlık analizi gerinim ve güvenirliğin doğal bir bileşimidir ve iç güvenirlik 
analiziyle ortaya çıkarılamayan en küçük düzeltmenin neden olduğu deformasyon direncinin belirlenmesi olarak tanımlanabilmektedir. Geometrik gerinim analizleri ağın potansiyel deformasyonunu daha ayrıntılı olarak algılayabilmek için, ağın datumundan bağımsız olarak gerçekleştirilebilmektedir (VANICEK ve diğ., 2001).

Gerinim kavramı yer değiştirme kavramı ile yakından ilgilidir ve eksenler yönündeki koordinat değişimlerinin ilk koordinatlara oranı şeklinde açıklanmaktadır. Aynı yapıda ve çok küçük gerilmelerin varsayıldığ 1 bir gerinim analizi ile afin dönüşümü birbirine benzetilmektedir (Acar ve diğ., 2008). Gerinim analizi ardışık iki ölçü periyodu arasinda nokta hareketlerinin deformasyon modeli ile birlikte değerlendirilmesidir.

Herhangi bir noktada ortaya çıkan yer değiştirme;

$\Delta x_{i}=E_{i} x_{i}+c_{0}$

olarak yazllabilir. Gerinim (deformasyon) matrisi (Ei) ya da tensor gradiyenti (eğimi);

$E_{i}=\operatorname{grad}\left(\Delta x_{i}\right)=\left[\begin{array}{cc}\frac{\partial v_{x i}}{\partial x} & \frac{\partial v_{x i}}{\partial y} \\ \frac{\partial v_{y i}}{\partial x} & \frac{\partial v_{y i}}{\partial y}\end{array}\right]=\left[\begin{array}{ll}e_{x x} & e_{x y} \\ e_{y x} & e_{y y}\end{array}\right]$ (26)

olarak düzenlenir. Genel anlamda gerinim matrisi (E)

$E=S+A$

olmak üzere simetrik ve antisimetrik olarak iki bölüme ayrılır (VANICEK ve diğ., 2001;

KONAK ve KÜREÇ, 2014).

\section{- Simetrik bölüm:}

$S=\left[\begin{array}{cc}\frac{\partial v_{x i}}{\partial x} & \frac{1}{2}\left(\frac{\partial v_{x i}}{\partial y}+\frac{\partial v_{y i}}{\partial x}\right) \\ \frac{1}{2}\left(\frac{\partial v_{x i}}{\partial y}+\frac{\partial v_{y i}}{\partial x}\right) & \frac{\partial v_{y i}}{\partial y}\end{array}\right]=\left[\begin{array}{cc}\varepsilon_{x x} & \varepsilon_{x y} \\ \varepsilon_{x y} & \varepsilon_{y y}\end{array}\right]$

\section{- Antisimetrik bölüm:}

$A=\left[\begin{array}{cc}0 & \frac{1}{2}\left(\frac{\partial v_{x i}}{\partial y}-\frac{\partial v_{y i}}{\partial x}\right) \\ \frac{1}{2}\left(\frac{\partial v_{y i}}{\partial y}-\frac{\partial v_{x i}}{\partial x}\right) & 0\end{array}\right]=\left[\begin{array}{cc}0 & -w \\ w & 0\end{array}\right]$ (29)

Hızların yerel bir koordinat sistemine dönüştürüldüğü durumlarda; gerinim elemanları, iki boyutlu genişletilmiş Helmert dönüşümü modelinin kullanılarak da hesaplanabilmektedir.

Bir jeodezik kontrol noktası için, farklı iki ölçü anında (epokta) elde edilen üç boyutlu konum farkları ya da hızları yardımıyla $\left[\begin{array}{l}v_{x} \\ v_{y} \\ v_{h}\end{array}\right]=\left[\begin{array}{ccc}-\sin \varphi \cos \lambda & -\sin \varphi \sin \lambda & \cos \varphi \\ -\sin \lambda & \cos \lambda & 0 \\ \cos \varphi \cos \lambda & \cos \varphi \sin \lambda & \sin \varphi\end{array}\right] \cdot\left[\begin{array}{l}v_{x} \\ v_{y} \\ v_{z}\end{array}\right]$ (30a)

$v_{k}=R v_{x}$

iki boyutlu bir yer değiştirme vektörü elde edilir (KÜREÇ, 2010). Epok sayısı (k) olmak üzere her bir ağ noktası için, (28) ve (29) eşitlikleri kullanılırsa;

$v_{x_{k+1}}=x_{k+1}-x_{k}=t_{x}+\varepsilon_{x x} x_{k}+\varepsilon_{x y} y_{k}-w y_{k}$ (31a)

$v_{y_{k+1}}=y_{k+1}-y_{k}=t_{y}+\varepsilon_{y x} x_{k}+\varepsilon_{y y} y_{k}+w x_{k}$

eşitliği ile iki boyutlu genişletilmiş Helmert modeli kurulur.

$\dot{v}_{i}=H_{i} g$

$H_{i}=\left[\begin{array}{cccccc}1 & 0 & x_{k} & y_{k} & 0 & -y_{k} \\ 0 & 1 & 0 & x_{k} & y_{k} & x_{k}\end{array}\right]_{i}$

(33)

$d_{i}^{T}=\left[\begin{array}{ll}v_{x_{k+1}} & v_{y_{k+1}}\end{array}\right]_{i}$

Gerinim parametreleri;

$g^{T}=\left[\begin{array}{llllll}t_{x} & t_{y} & \varepsilon_{x x} & \varepsilon_{x y} & \varepsilon_{y y} & w\end{array}\right]$

için oluşturulan bu eşitlik, eşlenik noktalar için düzenlenerek dengelemeli bir dönüşüm işlemi gerçekleştirilir ve gerinim elemanları $g=\left(H^{T} H\right)^{-1} H^{T} d$

elde edilir. Bunun yanı sıra aynı işlem adımları Afin Dönüşümüne göre oluştulan 


$$
H_{i}=\left[\begin{array}{cccccc}
1 & 0 & x_{i} & y_{i} & 0 & 0 \\
0 & 1 & 0 & 0 & x_{i} & y_{i}
\end{array}\right]
$$

dönüşüm matrisi kullanılarak da yapılabilmektedir. $\mathrm{Bu}$ durumda elde edilen gerinim elemanları

$$
g^{T}=\left[\begin{array}{llllll}
t_{x} & t_{y} & e_{x x} & e_{y x} & e_{x y} & e_{y y}
\end{array}\right]
$$

şeklindedir ve 2 boyutlu simetrik özellikli rasgele gerinim elemanları (tensörleri), (27) eşitliğinden yararlanılarak elde edilebilmektedir.

\section{DEFORMASYON SONUÇLARININ YORUMLANMASI}

Jeodezik ağların herhangi bir bölgesindeki deformasyon sonuçları, gerinim elemanlarından yararlanılarak grafik ve istatistik yöntemlerle yorumlanabilmektedir. (URL, 2012) $\mathrm{Bu}$ amaçla gerinim elemanların doğrusal bir fonksiyonundan elde edilen belli başlı parametreler kullanılmaktadır.

Gerinim parametreleri birimsiz oldukları ve bir oranı temsil ettikleri için "normal birim deformasyon" olarak adlandırılmaktadır (ACAR ve diğ., 2008). Gerinim elipslerinin elemanları da: Gerinim elipsinin büyük yarı ekseni,

$e_{1}=\frac{1}{2}\left(\varepsilon_{x x}+\varepsilon_{y y}+e\right)$

gerinim elipsinin küçük yarı ekseni,

$e_{1}=\frac{1}{2}\left(\varepsilon_{x x}+\varepsilon_{y y}-e\right)$

ve en büyük gerinim oranının yönü,

$\tan 2 \theta=\frac{2 \varepsilon_{x y}}{\varepsilon_{x x}-\varepsilon_{y y}} ; \theta \in\left[-\frac{\pi}{2}, \frac{\pi}{2}\right]$

$e=\sqrt{\left(\varepsilon_{x x}-\varepsilon_{y y}\right)^{2}+4 \varepsilon_{x y}^{2}}$

formülleri ile hesaplanır (Cai ve Grafarend 2007, Acar ve di $\breve{g}$. 2008). Hesaplanan $e_{1}$ ve $e_{2}$ yarı eksenleri $\lambda_{1}$ ve $\lambda_{2}$ özdeğerlerine karşılık gelmektedir (CAI ve GRAFAREND, 2007). $\lambda_{1}$ ve $\lambda_{2}$ özdeğerlerinin işaretlerine göre $\lambda_{1}$ ve $\lambda_{2}$ yönündeki gerinimin daralma ya da genişleme şeklinde olduğuna karar verilmektedir (Cai ve Grafarend, 2007). Yer kabuğu haraketlerinin yorumlanması için, özdeğerlerin birer fonksiyonu olarak hesaplanabilen:

- $45^{0}$ doğrultudaki en büyük kesme gerilmesi

$\gamma_{\max }=2 \sqrt{\frac{\left(\varepsilon_{x x}-\varepsilon_{y y}\right)^{2}}{2}+\varepsilon_{x y}^{2}}=\frac{\lambda_{1}-\lambda_{2}}{2 \sqrt{\lambda_{1} \lambda_{2}}}$

- Alansal Gerinim

$\gamma_{i Z}=i z\left(E_{i}\right)=\lambda_{1}+\lambda_{2}$

- İkinci ve üçüncü değişmezler

$\gamma_{D E T}=\operatorname{det}\left(E_{i}\right)=\lambda_{1} \lambda_{2}$

temel parametreler olarak kullanılmaktadır.

\subsection{Gerinim Elemanları için Hipotez Testleri}

A $\breve{g}$ noktalarındaki yer değiştirmelerin/ hızların doğrusal bir fonksiyonu olarak elde edilebilen gerinim elamanlarının güvenirliği ve anlamlılığ 1 , ardışık iki ölçme anından elde edilen duyarlık bilgilerinden yararlanarak, doğrusal hipotez testleri ile irdelenir. $\mathrm{Bu}$ irdeleme işlemleri gerinim alanının yapısı ve anlamlılığı olarak ayrı ayrı gerçekleştirilir. $\mathrm{Bu}$ amaçla gerçekleştirilen test işlemleri de ağın

- Anlamlı bir yer değiştirme kuşkusu bulunan noktaların dağılımna bakılarak Nokta Grupları biçiminde alansal,

- Ağın ölçme planına bağlı kalınarak; üçgen ya da çokgenler biçimine alansal

- Ağın ölçme planına ve ağ noktlarının konumlarına bağlı kalınarak noktasal olmak üzere irdelenebilir.

\subsubsection{Duyarlık hesapları}

Jeodezik ağın yapısına göre (5) ya da (21) bağıntılarına göre; iki ölçme anı arasındaki hız vektörünün ters ağırlık matrisi $\left(Q_{\dot{v} \dot{v}}\right)$ elemanlarından yaralanarak Varyans Kovaryans Matrisi: 


$$
K_{\dot{x} \dot{x}}=s_{0}^{2}\left(Q_{\dot{x} \dot{x}}\right)
$$

oluşturulur. Yerel bir koordinat sistemi kullanılması durumunda; (46) eşitliğinden

$Q_{\text {yerel }}=R\left(Q_{x \dot{x}}\right) R^{T}$

olmak üzere, hızların ağırlıkları

$$
P=\left(Q_{\text {yerel }}\right)^{-1}
$$

olarak elde edilir.

Hız alanının öncül ortalama hatası $\left(s_{0}\right)$ iki farklı ölçme anında değerlendirilen $s_{0 i}^{2}=\left(\frac{v^{T} P v}{f}\right)_{i}$ deneysel varyans bilgilerinden yararlanarak;

$s_{0}= \pm \sqrt{\frac{f_{1} s_{01}^{2}+f_{2} s_{02}^{2}}{f_{1}+f_{2}}}$

bağıntısından hesaplanır.

A $\breve{g}$ noktalarının hızları, duyarlıkları ve korelasyonları farklı dolaylı ölçüler olarak ele alınırsa; gerinim elemanlarının kesin değerleri ve duyarlık bilgileri (36) eşitliği yerine

$g=\left(H^{T} P H\right)^{-1} H^{T} P d$

biçiminde kurulan iki boyutlu genişletilmiş dengelemeli benzerlik dönüşümü modeli yardımıla hesaplanır. Gerinim bilinmeyenlerinin duyarlık bilgileri

$$
K_{g g}=s_{0}^{2}\left(H^{T} P H\right)^{-1}
$$

biçiminde kurulan Varyans-Kovaryans Matrisi ile elde edilir.

\subsubsection{Global Uyum Testleri}

Farklı iki ölçme anında değerlendirilen jeodezik ağdan elde edilen deneysel varyanslar, hiz ya da gerinim alanının hakkında öncül bilgileri barındırırlar. Her iki ölçme anında beklenen olası bir yer değiştirmenin anlamlı olup olmadığ 1 ve gerinim alanının yapısı hakkında bir karara varabilmek için deformasyon analizinde olduğu gibi global bir uyum testi gerçekleştirilir. $\mathrm{Bu}$ amaçla yer değiştirme vektörü $(d)$ için Sıfır Hipotezi ve Çift Yönlü Seçenek Hipotezi

$H_{0}: E\{d\}=0$
$H_{s 2}: E\{d\} \neq 0$

ayr1 ayrı kurulur. Test Büyüklüğ̈̈

$T=\frac{d^{T} Q_{d d}^{+} d}{m_{0}^{2} h}$

hesaplanır ve Sifir hipotezi, yanılma olasıllğ 1 0.05 seçilerek 0.95'lik bir istatistik güvenle sinanir.

Global uyum testleri ağın tamamı yerine yer değiştirme kuşkusu bulunan herhangi bir bölgesi için eşlenik noktalar kümesinde gerçekleştirilebilir. Herhangi bir nokta grubu/alan için hesaplanan deformasyon modelinin hesaplanan Test büyüklüğü

$T=\frac{d^{T} Q_{d d}^{-1} d}{m_{0}^{2} h}$

Fisher dağılımına uyar. Test büyüklüğünün deneysel değeri, Fisher dağılımının sınır değeri $\left(q=F_{h, 2 p-4,1-\alpha / 2}\right)$ ile karşılaştırılır. $\mathrm{Bu}$ test işlemi sonucunda $T>q$ koşulu gerçekleşirse, ele alınan alanda 0.95 istatistik güvenle anlamlı bir yer değiştirme olabileceğine karar verilir.

Başlangiçta deformasyon ağı olarak tasarlanmayan özel amaçlı sıklaştırma ağları ya da yüzey ağlarında (53) eşitliği ile kurulan test modeli yerine, kuramsal olarak ayn sonuçları veren ve dengelemeli benzerlik dönüşümleri sonuçlarına uygulanan doğrusal hipotez testleri kullanılır.

Global uyum testleri; datum koşulunun genişletilmiş helmert modeli üzerinden belirlenmesi durumunda, ele alınan alanda faklı bir ağırlık merkezine bağlı bir hareket modelinin varlığ 1 da test edilmiş olur (EVENTZUR, 2006).

\subsubsection{Gerinim Elemanları için Doğrusal Hipotez Testleri}

Herhangi bir nokta grubunda/alanda olası bir yer değiştirmeden kaynaklanan anlamlı bir gerinim birikiminin olup olmadığını irdelemek için, (49) eşitliğindeki modelden 
elde edilen gerinim modelinin ters ağırlıklar matrisi:

$$
Q_{g g}=\left(H^{T} P H\right)^{-1}
$$

biçiminde oluşturulur. $\mathrm{Bu}$ durumda gerinim modelinin hesaplanan deneysel test değeri:

$$
T=\frac{g^{T} Q_{g g}^{-1} g}{m_{0}^{2} h}
$$

Fisher dağılımının sınır değeri $\left(q=F_{h, 2 p-4,1-\alpha / 2}\right)$ ile karşılaştırılır. Seçenek hipotezinin geçersiz çıkması durumunda sözü edilen alanda, 0.95 istatistik güvenle anlamlı bir gerinim birikiminden söz edilebilir.

Global anlamda herhangi bir gerinimin anlaml1 olup olmamas1, gerinimin yap1s1 hakkında kesin bir bilgi vermez. Gerinimin yapısını irdeleyebilmek için gerinim parametreleri ya da birer fonksiyonları için uygun doğrusal hipotezler kurulur ve bu testlerin geçerliliği ayrı ayrı sınanır.

Nokta gruplar1/alansal olarak hesaplanan gerinim elemanları için Sıfır Hipotezi ve Çift Yönlü Seçenek Hipotezi:

$$
\begin{aligned}
& H_{0}: E\left\{g_{i}\right\}=0 \\
& H_{s 2}: E\left\{g_{i}\right\} \neq 0
\end{aligned}
$$

biçiminde ayrı ayrı doğrusal hipotezler kurulur. Her bir gerinim parametresine ilişkin test büyüklüğ̈̈:

$$
T_{i j}=\frac{\left|g_{i}\right|}{\sqrt{\left(K_{g g}\right)_{i i}}}
$$

hesaplanır. Sifir hipotezi, yanılma olasılı̆g 0.05 seçilerek 0.95 'lik bir istatistik güvenle sinanir.

(57) eşitliğindeki test büyüklügü t-Student dağılımına uyar. Test büyüklüğünün deneysel değeri, t-Student dağılımının sınır değeri $\left(q=t_{2 p-4,1-\alpha / 2}\right)$ ile karşılaştırılır. $\mathrm{Bu}$ test işlemi sonucunda $T>q$ koşulu gerçekleşirse, ele alınan gerinim parametresinin 0.95 istatistik güvenle anlamlı olduğuna karar verilir. $\mathrm{Bu}$ işlemler diğer gerinim parametreleri için ayrı ayrı test edilir. Elde edilen sonuçlara göre gerinim alanların homojen ya da homojen olmayan özellikleri belirlenir.

Burada gerinim parametreleri tek başlarına anlamlı olsun ya da olmasin, bu parametrelerin doğrusal bir fonksiyonundan elde edilen genişleme ya da daralma gibi parametreleri için de aynı irdelemelerin yapılmas1 gerekir.

$\mathrm{Bu}$ amaçla gerinim parametrelerin doğrusal kombinasyonları ve hata yayılma ilkesine göre elde edilen ortalama hatalarından yararlanarak, her bir parametre için gerekli olan doğrusal hipotezler, (56) ve (57) eşitliklerine benzer biçimde ayrı ayrı kurulmalı ve sinanmalıdır (İNCE ve diğ., 2007; UZUN ve diğ., 2005).

Sözgelimi, daralma ya da genişleme yönündeki gerinimin anlamlılığı için aşağıdaki işlemleri gerçekleştirilir. $\quad \lambda_{1}$ özdeğeri:

$$
\begin{aligned}
& \lambda_{1}=\frac{1}{2}\left(\varepsilon_{x x}+\varepsilon_{y y}+e\right) \\
& \partial \lambda_{1}=\frac{\partial \lambda_{1}}{\partial \varepsilon_{x x}} d \varepsilon_{x x}+\frac{\partial \lambda_{1}}{\partial \varepsilon_{y y}} \varepsilon_{y y}+\frac{\partial \lambda_{1}}{\partial \varepsilon_{x y}} \varepsilon_{x y} \\
& (59 a) \\
& \partial \lambda_{1}=a_{i} d \varepsilon_{x x}+b_{i} \varepsilon_{y y}+c_{i} \varepsilon_{x y}
\end{aligned}
$$

biçiminde gerinim parametrelerinin bir fonksiyonu olarak doğrusallaştırılır ve hataların yayılma ilkesine uygulanarak,

$$
m_{\lambda 1}^{2}=\left[\begin{array}{lll}
a_{i} & b_{i} & c_{i}
\end{array}\right] K_{g g}\left[\begin{array}{l}
a_{i} \\
b_{i} \\
c_{i}
\end{array}\right]
$$

bağıntısı ile $\lambda_{1}$ özdeğerinin ortalama hatası ve $T_{i \lambda}=\frac{\left|\lambda_{i}\right|}{m_{\lambda 1}}$

$\lambda_{1}$ özdeğerinin deneysel test değeri elde edilir.

Sonuç olarak herhangi bir alanda anlamlı bir deformasyon olmasına karşın; afinliğe işaret eden gerinim parametreleri anlamalı 
çıkmıyorsa, burada homojen bir yer değiştirmeden söz edilebilir. Buna karşın sözü edilen parametreler anlamlı çıkarsa, yer değiştirme sonucunda anlamlı bir şekil bozukluğunun izlenmekte olduğu kanısına varılır. Bu şekil bozukluğunun aynı zamanda anlamlı bir daralma ya da genleşmeye neden olup olmadığı da test sonuçlarına bakılarak karar verilir.

\section{KOCAELI İZDOGAP GPS AĞI İÇİN ALGILAYABILIRLIK DEĞERLERI}

$\mathrm{Bu}$ çalışma için, bilimsel ve mühendislik amaçlı bir üniversite araştırma projesi kapsaminda izlenmekte olan Kocaeli IZDOGAP GPS Ağı sayısal uygulama modeli olarak seçilmiştir (Şekil 1). İZDOGAP GPS Ağı, Kuzey Anadolu Fay Zonu'nun bat1 bölümünü oluşturan İzmit-Sapanca Fay1 çevresinde yer almaktadır. Bilindiği üzere Arabistan plakası tarafından sıkıştırılmakta olan Anadolu Plakası, Kuzey Anadolu ve Doğu Anadolu Fayları boyunca batıya doğru kaçmaktadır. Bu durumun bir sonucu olarak Kuzey Anadolu Fay Kuşağının Doğu Marmara Bölgesini kateden k1smında, yıllık ortalama yer kabuğu hareket hızı 1-2 cm düzeyinde beklenmektedir (INCE vd., 1991). $\mathrm{Bu}$ nedenle bu bölgede tesis edilen doğal gaz iletim hatlarının çevrelerinde oluşan yer değiştirmeleri izlemek amaciyla bir GPS S1klaştırma ağı tesis edilmiştir. 106 noktadan oluşan Kocaeli İZDOGAP GPS Ağ için, tasarım aşamasında EKK yöntemine dayanan bir ağırlı optimizasyonu işlemi gerçekleştirilerek toplam 271 GPS bazından oluşan uygun bir ölçme planı elde edilmiştir (IZZDOGAP 2011).

Kocaeli İZDOGAP GPS Ağının 1. Epok gözlemleri 2009 yılında, 2. Epok gözlemleri ise 2010 y1lında-gerçekleştirilmiştir. 2. Epok gözlemleri 106 noktada 266 GPS baz ölçüsünden oluşmaktadır.

2009 y1lında ölçülen 4 nokta, 2010 y1lında tahrip edilmiş olarak bulunmuştur. Ağın geometrik şeklinde istenmeyen zayıflıkların oluşmaması için bu noktaların yakınlarında yeni noktalar tesis edilmiş ve eksik kalan ölçme işlemleri bu noktalara göre tamamlanmıştır.

$\mathrm{Bu}$ nedenlerle Kocaeli IZDOGAP GPS ağ1 Multivaryat Düzenli GPS Ağı yapısında ele alınarak, deneysel algilayabilirlik analizleri bu koşullar altında elde edilmiştir (Tablo 1). Tablo 1, sayısal uygulamanın gerinim analizi bölümü için belirlenen noktalar kümesinden oluşmaktadır. Bu ağda ulaşılan algılayabilirlik değerleri arasında tutarlı bir karşılaştırma yapabilmek amaciyla; 8 Türkiye Ulusal Temel GPS Ağı (TUTGA) ve 6 Ana GPS Ağ (AGA) noktası kullanılarak datum birliği sağlanmıştır.

KOCAELİ kenti için hizmet veren Doğal Gaz Yaşamsal Alt Yapı sistemini kontrol eden IZDPGAP GPS Sıklaştırma Ağı'ndan elde edilen sonuçlara göre; yer kabuğu hareketlerini algılayabilirlik düzeyleri;

> $\Delta \mathrm{t}=\sqrt{ } 2=1.41$ yıllık zaman aralı̆̆ 1 için; 2009 epoğundaki öncül kestirimlere göre, (dmin $=0.33$, dortanca $=0.49$, dmax $=0.94$; dort $=0.50) \mathrm{cm}$

2010 epoğundaki öncül kestirmlere göre, $($ dmin $=0.54$, dortanca $=0.66$, $\operatorname{dmax}=1.17$; dort $=0.67) \mathrm{cm}$, olarak elde edilmiştir (Şekil 2).

$>$ Her iki epok arasında geçen $\Delta \mathrm{t}=1.13$ yıllık gerçek zaman aralığına göre ulaşılan deneysel algılayabilirlik değerleri de $\quad(d m i n=0.57, \quad$ dortanca $=0.72$, dmax=1.36; $\quad$ dort $=0.75) \mathrm{cm} \quad$ olarak hesaplanmıştır (Şekil 3). 


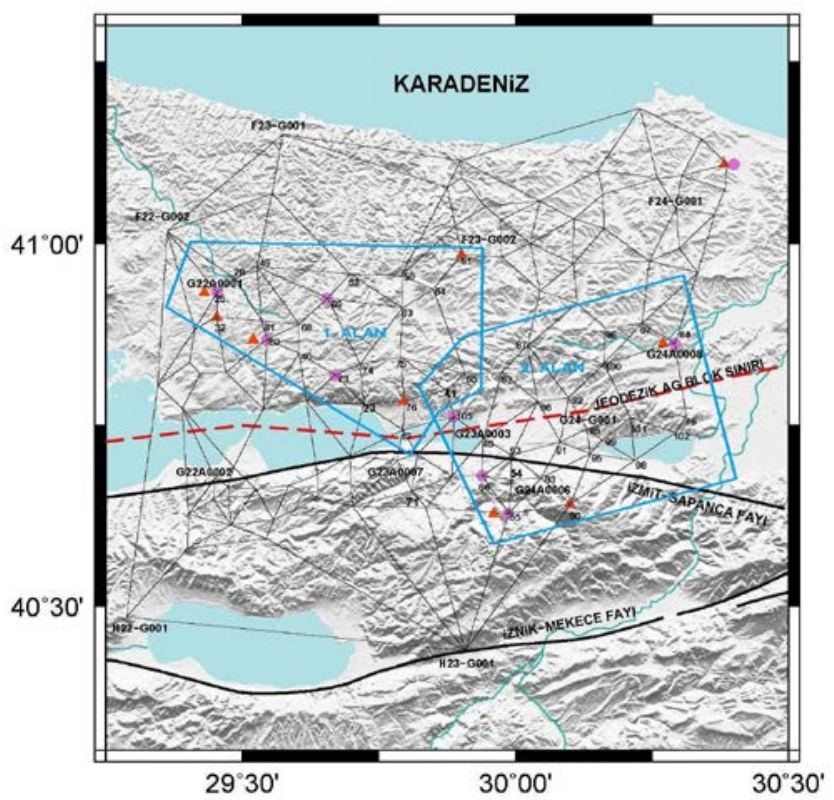

Şekil 1: Kocaeli İZDOGAP GPS Ağı 3 Boyutlu Helmert Dönüşümü Sonucu Uyuşumsuz Bulunan noktalar\ 3 Boyutlu Genișletilmiş Helmert Dönüșümü Sonucu Uyuşumsuz Bulunan noktalar )

Tablo 1: Kocaeli İZDOGAP GPS Ağı için Algılayabilirlik Değerleri

\begin{tabular}{|c|c|c|c|}
\hline Nokta No & $\begin{array}{c}\mathbf{2 0 0 9 . 3 7 0} \\
\mathbf{d}_{\text {min }} \\
(\mathbf{c m})\end{array}$ & $\begin{array}{c}\mathbf{2 0 1 0 . 4 9 6} \\
\mathbf{d}_{\text {min }} \\
(\mathbf{c m})\end{array}$ & $\begin{array}{c}\text { Deneysel } \\
\mathbf{d}_{\text {min }} \\
\mathbf{( c m})\end{array}$ \\
\hline $\mathbf{8 6}$ & 0.39 & 0.50 & 0.57 \\
\hline $\mathbf{4 3}$ & 0.32 & 0.58 & 0.59 \\
\hline $\mathbf{8 3}$ & 0.47 & 0.56 & 0.65 \\
\hline $\mathbf{9 2}$ & 0.39 & 0.52 & 0.59 \\
\hline $\mathbf{5 2}$ & 0.39 & 0.54 & 0.59 \\
\hline $\mathbf{6 5}$ & 0.37 & 0.56 & 0.60 \\
\hline $\mathbf{9 6}$ & 0.44 & 0.57 & 0.64 \\
\hline $\boldsymbol{*} \mathbf{8 4}$ & 0.56 & 0.97 & 1.00 \\
\hline $\mathbf{7 5}$ & 0.34 & 0.56 & 0.59 \\
\hline $\mathbf{7 6}$ & 0.32 & 0.64 & 0.63 \\
\hline $\mathbf{7 9}$ & 0.60 & 0.93 & 1.01 \\
\hline $\mathbf{1 0 5}$ & 0.32 & 0.52 & 0.55 \\
\hline $\mathbf{1 0 1}$ & 0.47 & 0.66 & 0.74 \\
\hline $\mathbf{8 5}$ & 0.42 & 0.57 & 0.65 \\
\hline $\mathbf{9 5}$ & 0.43 & 0.59 & 0.65 \\
\hline $\mathbf{9 8}$ & 0.51 & 0.66 & 0.75 \\
\hline $\mathbf{7 3}$ & 0.34 & 1.01 & 0.96 \\
\hline $\mathbf{7 4}$ & 0.34 & 0.64 & 0.65 \\
\hline$* \mathbf{6 0}$ & 0.40 & 0.67 & 0.70 \\
\hline $\mathbf{4 0}$ & 0.37 & 0.68 & 0.69 \\
\hline $\mathbf{6 8}$ & 0.40 & 0.65 & 0.68 \\
\hline $\mathbf{6 9}$ & 0.42 & 0.58 & 0.64 \\
\hline $\mathbf{6 3}$ & 0.36 & 0.53 & 0.57 \\
\hline$* 25$ & 0.50 & 0.78 & 0.82 \\
\hline & & & \\
\hline
\end{tabular}




\begin{tabular}{|c|c|c|c|}
\hline $\mathbf{3 2}$ & 0.47 & 0.73 & 0.77 \\
\hline $\mathbf{2 8}$ & 0.47 & 0.71 & 0.75 \\
\hline $\mathbf{4 9}$ & 0.45 & 0.62 & 0.68 \\
\hline $\mathbf{9 1}$ & 0.43 & 0.55 & 0.63 \\
\hline $\mathbf{8 7}$ & 0.41 & 0.48 & 0.57 \\
\hline $\mathbf{6 1}$ & 0.42 & 0.68 & 0.71 \\
\hline $\mathbf{1 0 2}$ & 0.66 & 0.87 & 1.00 \\
\hline *16 & 0.63 & 0.70 & 0.84 \\
\hline $\mathbf{6 2}$ & 0.44 & 0.59 & 0.65 \\
\hline $\mathbf{5 0}$ & 0.40 & 0.50 & 0.57 \\
\hline $\mathbf{6 4}$ & 0.41 & 0.47 & 0.56 \\
\hline $\mathbf{6 6}$ & 0.52 & 0.66 & 0.76 \\
\hline *: Her iki modelde de uyuşumsuz olan nokta çifti. \\
\hline
\end{tabular}

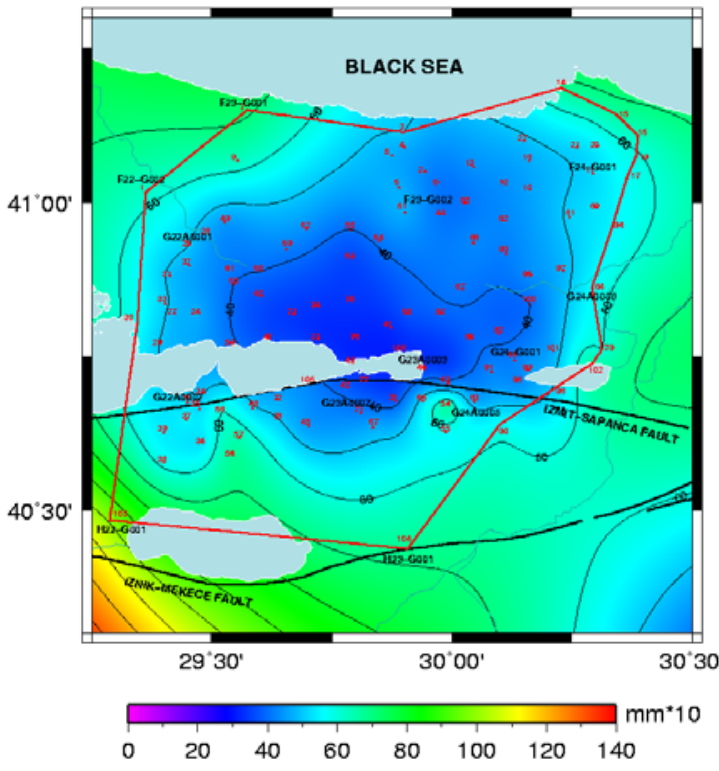

Epok 2009

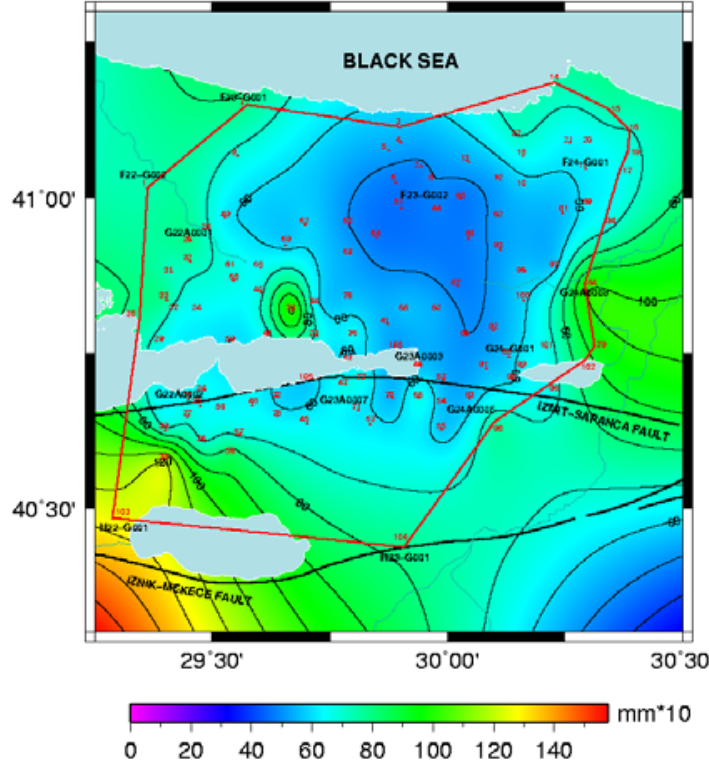

Epok 2010

Şekil 2: Kocaeli İZDOGAP GPS A $\breve{1}$ için Algılayabilirlik Haritaları (Eş yükseklik eğrilerinin birimi mm*10'dur.) 


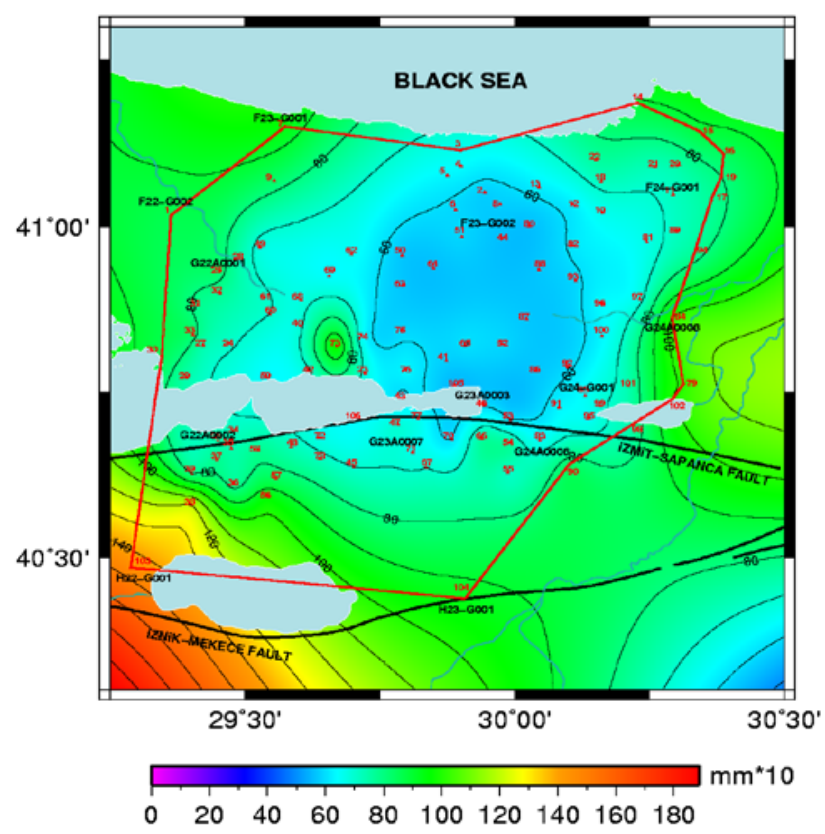

Şekil 3: Kocaeli İZDOGAP GPS Ağı için Deneysel Algılayabilirlik Haritası

(Eş yükseklik eğrilerinin birimi mm*10'dur.)

\section{KOCAELI İZDOGAP GPS AĞI IÇIN GERINIM İRDELEMELERI}

İDOGAP GPS ağının 2009 ve 2010 yıllarına ait gözlemleri, TUTGA ve AGA noktalarından seçilen eşlenik nokta kümesinde, kısmi iz minimum koşulu altında, serbest ağ yöntemine göre ayrı ayrı değerlendirilmiştir. Her iki epoktaki dengeleme sonuçları arasında, 3 Boyutlu Helmert ve 3 Boyutlu Genişletilmiş Helmert dönüşümleri kullanılarak eşdeğerlik testleri yapılmıştır.

Anlamlı bulunan yer degiştirme büyüklükleri;

- 3 Boyutlu Helmert Dönüşümünde; 84, 25, 16, 55, 60, 66, 69, 105 ve 73 numaralı ağ noktalar1

- 3 Boyutlu Genişletilmiş Helmert Dönüşümünde ise;

84, 25, 90, 16, 32, 51, 55, 60, 76 numaral1 ağ noktaları uyuşumsuz eşlenik noktalar kümesi olarak belirlenmiştir.

Bu sonuçlara göre;

- $84,25,16$ ve 60 numaralı noktalar her iki modelde de uyuşumsuz nokta çifti olarak yorumlanmaktadır. Diğer noktalar test sınır değerlerine oldukça yakın, $\alpha=0,05$ yanılma olasılığı altında eşdeğer olarak kabul edilebilecek noktalardır.

- Genişletilmiş helmert modelinde yanılma olasılığının biraz daha küçültülmesi durumunda, uyuşumsuz bulunan 90, 32, 51,55 ve 76 numaralı noktalarda zamanla anlaml bir gerinim birikiminin oluşabileceğini göstermektedir.

- Öte yandan Helmert modelinde uyuşumsuz görünmesine karşın, genişletilmiş modelde uyuşumlu bulunan 66, 69, 105 ve 73 numaralı noktalardaki değişimler, henüz homojen bir gerinim alanı için normal dağılımlı rasgele hatalar barındırmaktadırlar.

Her iki modelde de yer değiştirme kuşkusu bulunan noktalar kümesindeki dağılımları dikkate alınarak, gerinim elemanlarının davranışlarının irdelenebileceği iki ayrı nokta grubu belirlenmiştir. $\mathrm{Bu}$ gruplar sirasıyla 20 ve 24 eşlenik ağ noktasından oluşmaktadır. (Şekil 1).

- 2009 ve 2010 epoklarından elde edilen dengeli koordinatlar kullanılarak her alan için, Afin Dönüşüm matrisinden 
yararlanılarak gerinim parametreleri elde edilmiştir. Gerinim parametreleri için kurulan doğrusal hipotez testleri sonucunda, nokta gruplarına afinlik özellikleri istatistiksel olarak anlaml bulunmuştur. (Tablo 2, Tablo 3).
- Nokta grupları için elde edilen gerinim elipslerinin elemanlarına göre birinci grupta anlamlı bir genişleme/daralma birikimi belirlenmiştir. Her iki gruptaki $45^{\circ}$ doğrultusundaki kesme gerinimleri ile alansal gerinimler anlamlidir. (Tablo 4, Tablo 5).

Tablo 2: Gerinim Parametreleri

\begin{tabular}{|c|c|c|c|c|c|c|c|}
\hline \multirow{2}{*}{$\begin{array}{c}\text { Alan } \\
\text { No }\end{array}$} & \multirow{2}{*}{$\begin{array}{l}\text { İstasyon } \\
\text { Noktaları }\end{array}$} & \multicolumn{6}{|c|}{ Gerinim Parametreleri } \\
\hline & & $t_{x}(\mathrm{~cm})$ & $t_{y}(\mathrm{~cm})$ & $e_{x x}$ & $e_{y x}$ & $e_{x y}$ & $e_{y y}$ \\
\hline 1 & $\begin{array}{l}25,32,28,49,61, \\
60,68,40,73,74, \\
69,62,50,63,64, \\
75,76,43,65,51\end{array}$ & -0.2899 & 0.3070 & $6.68484 \mathrm{E}-07$ & 1.17112E-06 & $-4.91570 \mathrm{E}-07$ & 1.39499E-06 \\
\hline 2 & $\begin{array}{l}\text { 65,105,16,66,55, } \\
53,52,87,86,91, \\
83,90,92,100,96, \\
97,84,79,101,102, \\
85,99,95,98\end{array}$ & 0.0843 & -1.1557 & $-6.43318 E-08$ & 8.78721E-07 & $-7.25480 \mathrm{E}-07$ & $1.21926 \mathrm{E}-06$ \\
\hline
\end{tabular}

Tablo 3: Deneysel m0 ile Gerinim Parametreleri için istatistiksel testler

\begin{tabular}{|c|c|c|c|c|c|c|}
\hline \multirow{2}{*}{ Parametreler } & \multicolumn{3}{|c|}{ Alan 1 m0=2.33 cm } & \multicolumn{3}{c|}{ Alan 2 m0=2.43 cm } \\
\cline { 2 - 7 } & $\begin{array}{c}\text { Test } \\
\text { Değeri }\end{array}$ & $\begin{array}{c}\text { Sinır } \\
\text { Değer }\end{array}$ & Yorum & $\begin{array}{c}\text { Test } \\
\text { Değeri }\end{array}$ & $\begin{array}{c}\text { Sinır } \\
\text { Değer }\end{array}$ & Yorum \\
\hline$t_{x}$ & 2.22 & 2.03 & Anlamlı & 0.82 & 2.02 & Anlamsız \\
\hline$t_{y}$ & 2.61 & 2.03 & Anlamlı & 12.32 & 2.02 & Anlaml \\
\hline$e_{x x}$ & 5.99 & 2.03 & Anlamlı & 0.55 & 2.02 & Anlamlı \\
\hline$e_{y x}$ & 6.37 & 2.03 & Anlamlı & 6.19 & 2.02 & Anlamlı \\
\hline$e_{x y}$ & 4.97 & 2.03 & Anlamlı & 6.76 & 2.02 & Anlamlı \\
\hline$e_{y y}$ & 8.21 & 2.03 & Anlamlı & 9.48 & 2.02 & Anlaml \\
\hline
\end{tabular}

Tablo 4: Gerinim Elipslerinin Elemanları

\begin{tabular}{|c|c|c|c|c|c|c|}
\hline $\begin{array}{c}\text { Alan } \\
\text { No }\end{array}$ & $\lambda_{1}$ & $\lambda_{2}$ & $\theta$ & $\gamma_{\max }$ & $\gamma_{\text {IZ }}$ & $\gamma_{D E T}$ \\
\hline $\mathbf{1}$ & $\begin{array}{l}1.16020 \mathrm{E}- \\
06\end{array}$ & $9.03269 \mathrm{E}-07$ & $46^{\circ} .91246$ & $\begin{array}{c}1.231828 \mathrm{E}- \\
06\end{array}$ & $2.06347 \mathrm{E}-06$ & $1.04797 \mathrm{E}-12$ \\
\hline $\mathbf{2}$ & $\begin{array}{c}1.21467 \mathrm{E}- \\
06\end{array}$ & $-5.97417-08$ & $83^{\circ} .19197$ & $\begin{array}{c}1.821724 \mathrm{E}- \\
06\end{array}$ & $1.15492 \mathrm{E}-06$ & $-7.25662 \mathrm{E}-14$ \\
\hline
\end{tabular}

Tablo 5: Deneysel m0 ile Gerinim Elipslerinin Elemanları için istatistiksel testler

\begin{tabular}{|c|c|c|c|c|c|c|}
\hline \multirow{2}{*}{ Parametreler } & \multicolumn{3}{|c|}{ Alan 1 m0=2.33 cm } & \multicolumn{3}{c|}{ Alan $\mathbf{2 ~ m 0 = 2 . 4 3 ~ c m ~}$} \\
\cline { 2 - 7 } & $\begin{array}{c}\text { Test } \\
\text { Değeri }\end{array}$ & $\begin{array}{c}\text { Sinır } \\
\text { Değer }\end{array}$ & Yorum & $\begin{array}{c}\text { Test } \\
\text { Değeri }\end{array}$ & $\begin{array}{c}\text { Sınır } \\
\text { Değer }\end{array}$ & Yorum \\
\hline$\lambda_{1}$ & 2.15 & 2.03 & Anlamlı & 7.25 & 2.02 & Anlamlı \\
\hline$\lambda_{2}$ & 1.46 & 2.03 & Anlamsız & 0.33 & 2.02 & Anlamsız \\
\hline
\end{tabular}




\begin{tabular}{|c|c|c|c|c|c|c|}
\hline$\gamma_{\max }$ & 3.28 & 2.03 & Anlaml1 & 5.24 & 2.02 & Anlamlı \\
\hline$\gamma_{\text {IZ }}$ & 2.51 & 2.03 & Anlamlı & 4.65 & 2.02 & Anlamlı \\
\hline$\gamma_{D E T}$ & 1.21 & 2.03 & Anlamsız & 0.32 & 2.02 & Anlams1z \\
\hline
\end{tabular}

\section{SONUÇ}

Yaşamsal bir alt yap1 olan KOCAELİ ili Doğal Gaz Alt Yapı Sistemi için tasarlanan Kocaeli IZDOGAP GPS sıklaştırma ağı Multivaryat düzenli bir yapıya sahiptir. $\mathrm{Bu}$ ağda ulaşılan algılayabilirlik değerleri arasında tutarlı bir karşılaştırma yapabilmek amaciyla, 8 TUTGA ve 6 AGA noktası kullanılarak datum birliği sağlanmıştır.

$>$ Her iki epok arasında geçen $\Delta \mathrm{t}=1.13$ yıllık gerçek zaman aralığına göre ulaşılan deneysel algılayabilirlik değerleri $\left(\mathrm{d}_{\min }=0.57, \quad \mathrm{~d}_{\text {ortanca }}=0.72, \quad \mathrm{~d}_{\max }=1.36\right.$; $\left.\mathrm{d}_{\text {ort }}=0.75\right) \mathrm{cm}$ olarak hesaplanmıştır. $\mathrm{Bu}$ değerler 2009 ve 2010 y1llarında $\Delta t=\sqrt{ } 2=$ 1.41 öncül olarak kestirilen değerlerle uyumludur.

> Ulaşılan öncül ve deneysel algılayabilirlik değerleri, Kocaeli İDOGAP GPS Ağ1 noktalarının, bölgede beklenen yerkabuğu hareketlerini yeterince algilayabilecek düzeyde olduğunu göstermektedir.

> İki epok için gerçekleştirlen eşdeğerlik testleri ile yer değiştirme kuşkusu bulunan noktalarda afinlik yönünde anlamlı gerinim birikimleri gözlenmiştir.

Kuşkulu noktalar kümesinin iki ayrı gruba ayrilmas1 durumda; kesme gerinimleri ile alansal gerinimler anlamlı olarak belirlenmiştir. Birinci nokta grubunda anlamlı bir genişleme/daralma birikiminden söz edilebilir.

\section{KAYNAKÇA}

Aksoy, A., Ayan, T., Deniz, R., Yalın, D., Karasu, H., Seeger, H., Franke, P., Altıner, Y., Hirsch, O., Bautsch, P.,(1995), Türkiye'de Yer Kabuğu Hareketlerinin Yersel Jeodezik Yöntemlerle Belirlenmesi Çalış̧maları, Türk Haritacılığının 100. Yılı TUJJB ve
TUFUAB Kongreleri Bildiriler Kitabı Cilt 2, pp. 358-369, Ankara, Türkiye.

Even-Tzur G., (2006): Datum Definition and its Influence on the Sensitivity of Geodetic Monitoring Networks, 12th FIG Symposium, 4-9.

Hsu, R. ve Hsiao, K., (2002), Pre-Computing The Sensitivity of a GPS Station for Crustal Deformation Monitoring, Journal of the Chinese Institute of Engineers, 12-15.

İnce, C. D., Konak, H. ve Arslan, O., (2007), Deprem Hasarlarının İlenmesi Amaciyla Uydu Görüntülerinden Elde Edilen Konumsal Veri Yı̆̆ınlarının Iyileştirilmesi, International Earthquake Symposium Kocaeli.

İnce, C. D., Baykal, O., Çakmak, R., Dikbaş, A., Erden, T., Ergintav, S., İpbüker, C., Özşamlı, C., Şahin, M., Tarı, E., Tarı, U. and Tüysüz, O. (2001), GPS Measurements along the North Anatolian Fault Zone on the Mid-Anatolian Segment, Proceedings of International Symposium and Exhibition, Geodetic Photogrammetric and Satellite Technologies-Development and Integrated Application, 351-359, Sofia.

İZDOGAP (2011),Monitoring of IZGAZ-Natural Gas Infrastructure using National Geodetic Networks and Land Information Systems (IZDOGAP), Technical Reports (Turkish), Ed. Haluk Konak, A Project of Scientific Research, Kocaeli University.

Konak, H. ve Ekinci, Ö., (2005), Yaşamsal Altyapı Sistemlerinin İzlenmesi, Mimarizm Dergisi, Özel Sayı, Nisan, 118-121.

Küreç, P., ( 2010), Yüzey ağlarının değerlendirilmesi, KOÜ Fen Bilimleri Enstitüsü, Kocaeli.

Küreç, P. ve Konak, H., (2011), Siklaştırma GPS Ağlarının yer kabuğu hareketlerine karşl duyarliklart ve olast algulayabilirlik düzeyleri, hkm Jeodezi, Jeoinformasyon ve Arazi Yönetimi Dergisi, Özel Sayı, sayfa: 84-90. 
Küreç, P. ve Konak, H., (2014), A priori sensitivity analysis for densification GPS networks and their capacities of crustal deformation monitoring: a real GPS network application, Nat. Hazards Earth Syst. Sci.

14, 1299-1308.

Uzun, S., Konak, H. ve Dilaver, A., (2005), Saylsallaștırma Modelleri ve Sayısallaştırılmış Harita Konum Bilgilerinin Güvenirliği, TMMOB Harita ve Kadastro Mühendisleri Odas1 10. Türkiye Harita Bilimsel ve Teknik Kurultayı, 28 Mart- 1 Nisan, Ankara.

URL 1., (2012), Algorithm for computing infinitesimal strain rate between three noncolinear GPS satations, given their $\mathrm{N}-\mathrm{S}$ and $E-W$ velocities, with a worked example, Version of September 8, 2012, Vince_Cronin@baylor.edu., presor@wesleyan.edu 